УДК 070+811.111

10.00.00 Филологические науки

СУЩНОСТЬ И СТРУКТУРНЫЕ КОМПОНЕНТЫ ПЕЧАТНЫХ МАТЕРИАЛОВ

Бутко Елена Сергеевна

Кубанский государственный технологический университет,

350072, Российская Федерация, г. Краснодар, ул. Московская, 2;

электронная почта: butkohelen@mail.ru

PR-публицистика сегодня стала неотъемлемой частью жизни современного общества. Мы сталкиваемся с ней не только в средствах массовой информации. Она проникает во все сферы человеческой деятельности, и оказывает серьезное влияние на общественное сознание. Поистине этот жанр в печатных СМИ сегодня многолик, вездесущ и разнообразен. В России он стал не только частью экономики, но и частью массовой культуры.

Интерес обусловлен и тем, что сам по себе текст является одной из наиболее сложных в семиотическом плане информационновоздействующих моделей. Таким образом, можно констатировать, что абсолютная вовлеченность каждого из нас в сферу его воздействия и определяет в конечном итоге то место, которое он сегодня занимает, в том числе в области гуманитарных исследований

КЛючевЫе слова: ПЕЧАТНЫЕ СМИ, ЛИНГВИСТИЧЕСКИЕ СРЕДСТВА, ИЗДАНИЯ, ДИСКУРС, ПРАГМАТИЧЕСКИЕ ХАРАКТЕРИСТИКИ, КОММУНИКАТИВНОСТЬ

Doi: 10.21515/1990-4665-123-090
UDC $070+811.111$

Philology

\section{ESSENCE AND STRUCTURAL COMPONENTS OF PRINTED MATERIALS}

Butko Elena Sergeevna

Kuban State Technological University, 350072, Russian Federation, Krasnodar, st. Moscowskay, 2;

e-mail: butkohelen@mail.ru

PR-journalism today has become an integral part of modern life. We are faced with it not only in the media. It enters into all spheres of human activity, and has a serious impact on the public consciousness. Indeed, today this genre in print media is multifaceted, ubiquitous and diverse. In Russia he became not only a part of the economy, but also a part of the mass culture. Interest is due to the fact that the text is one of the most complex in semiotic terms of information and impact models. Thus, we can say that the absolute involvement of each of us in its sphere of influence can determine the place that genre occupies today, including the field of humanitarian studies

Keywords: PRINTED MASS-MEDIA, LANGUAGE RESOURCES, PUBLISHING, DISCOURSE, PRAGMATIC CHARACTERISTICS, COMMUNICATION

Doi: 10.21515/1990-4665-123-090

В современном мире активно развиваются новейшие системы коммуникации, разрабатываются и совершенствуются формы, методы передачи информации самого разнообразного характера. Рассматривая ряд наиболее эффективно действующих систем можно выделить печатное издание, которое занимает одно из самых важных мест в качестве уникального семиотического феномена. В настоящее время оно успешно адаптируется к сложнейшим современным условиям, реализуется в различных вариантах, например, электронный вид СМИ. 
Актуальность данной темы соотносится со значимым положением печатных материалов в современном обществе.

Можно установить на всех основаниях, что процесс взаимодействия содержательной и формальной структур печатного издания становится все более усложненным и многоаспектным, а приемы создания текста становятся все более значимыми, требуют серьезного исследования с целью поиска путей дальнейшего повышения их эффективности.

Основной целью данного исследования является анализ условий и способов организации печатного текста, а также описание структурносемантических особенностей его функционирования.

Объектом исследования выступают англоязычные печатные CMИ PRжанра.

Предметом исследования являются структурно-семантические особенности организации печатного текста.

Основная цель определила решение следующих задач:

- обосновать теоретическую основу существования и развития PRжанра как особого типа дискурса;

- выявить и описать особенности функционирования англоязычного новостного дискурса.

Теоретической базой исследования послужили теоретические, научнометодические, учебно-методические и научно-популярные произведения зарубежных и русскоязычных авторов второй половины XX столетия, посвященные рассмотрению проблем лингвистики текста, смежных и общегуманитарных вопросов: работы Т. Ван Дейка, В. Кинтча, Т. Андерсона, М. Бернштейна и Дж. Болтера, Г. Брауна, П. Фолтца, Е.С.Кубрякой, А.А Кибрика., Н.Д. Арутюновой, В.3. Демьянкова, А.Н. Васильевой, И.А. Зимней и других ученых.

Методика исследования имеет комплексный характер: используются сравнительный семантический анализ, методы дискурсного анализа. При http://ej.kubagro.ru/2016/09/pdf/90.pdf 
этом при анализе мы избегали рассмотрения поверхностных структур текста в отрыве от их коммуникативных аспектов.

Печатное издание можно рассматривать как результат сложного и длительного процесса, непосредственно затрагивающего социальную, духовную, эстетическую, политическую, экономическую, производственную, технологическую сферы. На различных исторических этапах развития СМИ было отмечено не только размеренное эволюционирование, но порой и впечатляющие резкие скачки с соответствующими качественными изменениями. Но, несмотря на некоторые противоречия отдельных этапов этого процесса, этот процесс двигался в едином направлении.

Любое по типу печатное издание, страница как его неотъемлемый конструктивный элемент - это целостный комплекс с характерными взаимообусловленными семантическими и формальными признаками, в котором идеально-образное начало неразрывно связано с материальнопредметным. Эта диалектическая взаимосвязь носит глубинный и далеко не всегда отчетливо алгоритмируемый характер в силу большой усложненности, многоаспектности и воздействия структур и системообразующих факторов.

Именно широкий круг проблем соотношения содержательных и формальных структур печатного издания заставляет глубинно исследовать сущность и структурные компоненты печатных материалов, достаточно репрезентативно отражающих важные процессы, протекающие в коммуникативной области.

Говоря о воздействии системообразующих факторов и признавая их значительную роль в воссоздании единого завершенного комплекса печатного издания, все же обращаемся главным образом к факторам структурообразующим, в связи с чем, и проводим грань между этими двумя категориями.

http://ej.kubagro.ru/2016/09/pdf/90.pdf 
Структурированные содержательные и формальные составляющие такого многоуровневого, многомерного объекта, каким является печатное издание, предстают как обширные знаковые объединения, образующие целостное текстовое пространство. Простые единицы смысла, например, семы, порождаемые знаками, а также такие сложные образования как тексты, занимают, несомненно, приоритетное место в данной системе. И знаки и тексты обладают соответствующей структурностью, исследовав которую, можно говорить о содержательной и формальной составляющей.

Данный подход поможет избирательно, многопланово исследовать печатное издание в целом, затем выйти на отдельную страницу, абзац, предложение, словосочетание и в итоге детально разобрать сему. Это выведет на уровень необходимых обобщений, заключений и концептуальных выводов.

Обращаясь к работам М. Н. Куфаева, который предпринял попытку типологической классификации печатного издания, исходя из семантического и формального различия тех или иных его образцов, можно конкретизировать объект нашего исследования, а именно печатное издание [1, с.122]. В нашем случае мы можем провести аналогию с понятием «книга», о которой ведет речь Куфаев. Его понятие отличается тем, что книга, является тем, что посредством видимого знака зафиксированы мысль и слово, взятые вместе. Именно это и есть определяющая характерная особенность, которая должна быть присуща книге. Соответственно делается и вывод о том, что все содержание книги должно подчиняться единой структуре и формальному содержанию.

В нашем случае, признавая справедливость суждений книговеда, можно говорить о перенесении свойств понятия «книги» на «печатное издание», которому имманентны «мысль и слово» в трактовании Куфаева.

Освещение вопроса даст возможность достаточно адекватно взглянуть на роль знака, и в частности символа, в конструировании общего плана http://ej.kubagro.ru/2016/09/pdf/90.pdf 
печатного издания. Все его формообразующие элементы участвуют в воссоздании единого дискурса на основе общей идейной и логической подпочвы, то есть соучаствуют в воспроизведении целостного текстуального пространства, связанного с окружающим миром и «погруженного в жизнь», которое обладает семантикой, и все его составляющие подразделы соответствующим образом прочитываются. Следовательно, в реализации коммуникативной функции активно участвуют не только собственно языковые средства, но и параязыковые. К ним мы отнесем все многообразие основных и вспомогательных средств, формирующих облик печатного издания.

Все они выполняют общую функцию - передают реципиенту визуальную информацию, восприятие которой порождает соответствующие идеи и чувства, влияющие на поведение индивида, принятие им тех или иных решений.

Печатное издание явление искусственное, так как оно создано человеком для человека. Деятельность СМИ оказывает исключительно большое влияние на жизнь общества в целом, на социальнопсихологический и нравственный облик каждого из членов этого общества, потому что всякая новая информация, поступающая по каналам СМИ, соответствующим образом стереотипизирована и несет в себе многократно повторяемые ценностные установки, которые закрепляются в сознании людей. Публицистический дискурс может быть рассмотрен и с точки зрения кодирования и декодирования смысла для коммуникантов. В нашем случае, при изучении печатного текста особое внимание следует уделить различиям устной и письменной форм передачи информации в ходе текстопорождения. Поскольку в отличие от устной коммуникации, где общий ход создания текста обеспечивается обязательным присутствием партнеров по коммуникации, в письменном дискурсе, в частности публицистическом, создается некая искусственная взаимная http://ej.kubagro.ru/2016/09/pdf/90.pdf 
зависимость между типом текста и исполнителем. Более того, текст готовится с учетом всех психо-физических качеств читателя, который находится лишь в абстрактном представлении автора.

Исследуя язык СМИ следует рассматривать печатные материалы, продуцируемые в данной сфере как вид деятельности, и фокусировать свое внимание на тех языковых средствах и техниках, употребление которых запланировано воздействуют на сознание адресата. В СМИ материал всегда адресован той или иной аудитории. Печатное издание является продуктом речевого акта, и инструментом для достижения определенной цели. В зависимости от тех или иных обстоятельств или условий, в которых совершается распространяется материал, он может либо достичь поставленную цель и тем самым оказаться успешным, либо не достичь ее. Чтобы быть успешным, печатное издание должно быть актуальным, уместным, востребованным иначе участников коммуникативного акта (адресата и адресанта) ждет коммуникативная неудача [2, с.64].

Изучение печатного издания, в качестве дискурса позволяет определить все составляющие коммуникативного акта, а именно: адресант, адресат, а также текст как носитель информации). Очевидно, что сама коммуникативная ситуация, реализованная в публицистическом дискурсе, отличается от устной ситуации общения, поскольку модель текста отражает жизненную ситуацию, но не является при этом моделью общения. В этом положении, по нашему мнению, отражена вся сложность текста [3, с.314].

M.M. Бахтин, описывая разнообразие возможных адресатов высказывания, говорил, что адресат «может быть непосредственным участником-собеседником бытового диалога, может быть дифференцированным коллективом специалистов какой-нибудь специальной области, может быть более или менее дифференцированной публикой, народом, современниками, единомышленниками, противниками http://ej.kubagro.ru/2016/09/pdf/90.pdf 
и врагами, подчиненным, начальником, низшим, высшим, близким, чужим и т.п., он может быть и совершенно неопределенным неконкретизированным другим (при разного рода монологических высказываниях эмоционального типа) - все эти виды и концепции адресата определяются той областью человеческой деятельности и быта, к которой относится данное высказывание»[4, с.237].

Анализируя условия успешности адекватного восприятия печатного издания предполагаем, что многие из этих условий связаны с адресатом, точка зрения которого принимается за отправную. Неудивительно, таким образом, что столь большое внимание уделяется фигуре адресата. Поскольку у автора есть только одна попытка донести информацию, которую он хотел передать. В отличие от устной коммуникации, когда сказанное можно пояснить, получить моментальную обратную реакцию от собеседника, разъяснить сказанное, задать обоюдные вопросы. В отличие от адресата в ситуации непосредственного диалогического общения адресант средств массовой коммуникации- это не присутствующий в ситуации коммуникативного акта реальный индивидуум, а потенциальное неопределенное множество лиц, которые могут взять в руки журнал или газету.

Следовательно, автор статей массовой информации сам создает своего типового адресата, при этом осуществляя коммуникативный акт, рассчитанный на определенную группу лиц, выделяемую по половому, возрастному, социальному, национальному, конфессиональному, мировоззренческому признакам.

Эффективным средством выявления законов функционирования языка, закономерностей употребления языковых единиц в соответствии с определенными целями говорящего служит аргументация. Именно поэтому в тексте газеты или журнала локально-темпоральная разобщенность партнеров по коммуникации лишает адресанта http://ej.kubagro.ru/2016/09/pdf/90.pdf 
возможности наблюдения за непосредственной реакцией адресата на прочитанное сообщение. При этом задача автора любой газетнопублицистической статьи не сводится просто к передаче сообщения. Специфика коммуникативной ситуации общения посредством текста печати требует поиска наиболее действенных в данном контексте средств воздействия на адресата. Прагматическая установка автора сообщения, рассчитанная на запрограммированный эффект (воздействие на адресата через установление с ним контакта), реализуется в выборе форм и средств изложения конкретного содержания [5, с.85].

Поиск средств оптимальной организации языкового материала газеты или журнала продиктован еще одним фактором. Нацеленность печатного текста на заполнение существующих у читательской аудитории информационных «лакун» (при постоянно возрастающем объеме адресатно-ориентированной информации, с одной стороны, и при сохранении относительной структурной жесткости формы газетного текста - с другой), заставляет адресанта искать дополнительные формы установления и поддержания контакта с адресатом. Однообразие и монотонность подачи материала может вызвать резкое снижение качества процесса взаимодействия источника информации (периодики) и ее адресата (читателя). Газетная (журнальная) информация должна быть организована четко, кратко, ярко.

Распределение интересов адресата в процессе удовлетворения информационных потребностей заставляет выделять одни части сообщения и выпускать из вида другие его элементы [6, с.408].

Огромное значение в поддержании речевого контакта с адресатом имеет тема текста. В подобной ситуации тема выполняет методическую функцию актуализации наиболее значимых в информационном отношении сегментов текста и облегчает селективное восприятие информационного потока. Единство темы или тем, их доступность и понятность для адресата, http://ej.kubagro.ru/2016/09/pdf/90.pdf 
а также правильность выбора темы позволяет укрепить единую базу текста и поддержать речевой контакт на всем его протяжении [7, с. 117].

Для газетного-публицистического текста характерно превалирование одной доминирующей темы, проходящей через весь текст от начала до конца[8, с.218]. Однако на протяжении текста, на разных его участках, в нее вклиниваются побочные темы разной степени значимости, которые вскоре прерываются, не получая дальнейшего развития, и обеспечивают возврат к основной тематике. В этом отношении семантическая структура построениятекста информационной статьи служит своего рода отступлением от основной тематической линии, реализуя одну из микротем в пределах главной темы газетного текста. Эта особенность структурно-семантической целостности служит эффективным средством удержания внимания адресата, упорядочения процесса восприятия текста, оживления повествования, способствует наиболее полному раскрытию темы газетной публикации, что играет важную роль в осуществлении двух главных функций текста публицистики - функции сообщения и функции воздействия [9, с. 12].

В итоге эффект воздействия зависит от выбора соответствующих средств в конкретной коммуникативной ситуации, языковых средств, употребление которых ориентировано на оптимальное решение конкретной коммуникативной задачи. Это может быть достигнуто, например, использованием адресантом языковых средств, апеллирующих к чувствам, желаниям, ожиданиям адресата. Вместе с тем в рамках публицистического дискурса адресант (журналист, автор статьи) не просто передает информацию адресату, но заинтересован в том, чтобы вызвать у него определенную реакцию (позитивную или негативную).

Таким образом, в рамках публицистического дискурса были рассмотрены использования лингвистических средств, которые участвуют в создании публицистического текста в его жанрово-специфической http://ej.kubagro.ru/2016/09/pdf/90.pdf 
организации, и в подготовке печатного издания в целом. В ходе данного исследования был проведен анализ коммуникативно-прагматических характеристик и языковых элементов публицистического дискурса, в котором при определенных условиях актуальное значение приобретают стилистические и прагмакоммуникативные аспекты языка.

\section{ЛИТЕРАТУРА} $188 \mathrm{c}$.

1. Куфаев М. Н., Проблемы философии книги. Книга в процессе общения. 2004. -

2. Городецкий Б.Ю., Кобозева И.М., Сабурова И.Г. $\quad$ К типологии коммуникативных неудач// Диалоговое взаимодействие и представление знаний. Новосибирск. 1985. - С. 64-78. $648 \mathrm{c}$

3. Арутюнова Н.Д. Логический анализ языка. Семантика начала и конца. 2002. -

4. Бахтин М.М. Эстетика словесного творчества. 1979. - 424 с.

5. Иссерс О.С., Речевое воздействие. 2009. - 224 с.

6. Гловинская М.Я., Глаголы со значением передачи информации // Язык о языке (ред. Н.Д. Арутюнова). М. Языки русской культуры. 2000. - С. 403-416.

7. Почепцов Г.Г., Коммуникативные технологии двадцатого века. 1999. - 200 с.

8. Алефиренко Н.Ф., Семененко Н.Н., Фразеология и паремиология. 2009. - 344 с.

9. ШвейцерА.Д., Социальная дифференциация английского языка в США. 1983. $216 \mathrm{c}$

\section{References}

1. Kufaev M. N., Problemy filosofii knigi. Kniga v processe obshhenija. 2004. - 188 s.

2. Gorodeckij B.Ju., Kobozeva I.M., Saburova I.G. K tipologii kommunikativnyh neudach // Dialogovoe vzaimodejstvie i predstavlenie znanij. Novosibirsk. 1985. - S. 64-78.

3. Arutjunova N.D. Logicheskij analiz jazyka. Semantika nachala i konca. 2002. - 648 S.

4. Bahtin M.M. Jestetika slovesnogo tvorchestva. 1979. - $424 \mathrm{~s}$.

5. Issers O.S., Rechevoe vozdejstvie. 2009. - 224 s.

6. Glovinskaja M.Ja., Glagoly so znacheniem peredachi informacii // Jazyk o jazyke (red. N.D. Arutjunova). M. Jazyki russkoj kul'tury. 2000. - S. 403-416.

7. Pochepcov G.G., Kommunikativnye tehnologii dvadcatogo veka. 1999. - 200 s.

8. Alefirenko N.F., Semenenko N.N., Frazeologija i paremiologija. 2009. - 344 s.

9. ShvejcerA.D., Social'naja differenciacija anglijskogo jazyka v SShA. 1983. - $216 \mathrm{~s}$. 